Article

\title{
Experiences of the Bariatric Pre-Surgery Evaluation Process in a National Health Service-An Interpretative Phenomenological Analysis
}

\author{
Karan Sahar ${ }^{1, *}$ and Afsane Riazi ${ }^{2}$ (D) \\ 1 Department of Psychology, Royal Holloway, University of London, Egham TW20 0EX, UK \\ 2 Psychology Department, Richmond, The American International University in London, \\ Richmond TW10 6JP, UK; Afsane.Riazi@Richmond.ac.uk \\ * Correspondence: Karan.Sahar.2008@live.rhul.ac.uk
}

Citation: Sahar, K.; Riazi, A. Experiences of the Bariatric Pre-Surgery Evaluation Process in a National Health Service-An Interpretative Phenomenological Analysis. Surgeries 2021, 2, 199-215. https://doi.org/10.3390/ surgeries2020021

Academic Editors: David Edelman and Giovanni Tarantino

Received: 13 May 2021

Accepted: 10 June 2021

Published: 12 June 2021

Publisher's Note: MDPI stays neutral with regard to jurisdictional claims in published maps and institutional affiliations.

Copyright: (c) 2021 by the authors. Licensee MDPI, Basel, Switzerland. This article is an open access article distributed under the terms and conditions of the Creative Commons Attribution (CC BY) license (https:// creativecommons.org/licenses/by/ $4.0 /)$.

\begin{abstract}
There is currently little understanding of bariatric patients' experiences and expectations of the bariatric pre-surgery evaluation (PSE) process. This is especially true for patients within the National Health Service (NHS) in the UK. Consequently, this study undertakes a qualitative study to explore the experiences and expectations of the bariatric PSE amongst patients who had undergone bariatric surgery within the NHS in the UK, using the Interpretative Phenomenological Analysis. Three inter-related superordinate themes were presented: (i) 'PSE was challenging but essential', (ii) 'Coping processes to deal with the PSE', and (iii) 'Staff and service evaluation'. Most participants had conflicting feelings about the PSE process as it had both positive and negative impacts on their wellbeing. The process was considered essential for preparation and successful post-surgery adjustment, though the uncertainty of approval was experienced as very distressing. Consequently, participants utilised both external and internal coping strategies, such as social support, researching, or 'toeing the line'. Participants' experiences encouraged them to provide feedback about the staff and service, which revealed a preference for a tailored evaluation process. The emerged themes represent an initial framework for helping healthcare providers and researchers to involve patients in service delivery thereby facilitating a patient-centred approach. A starting point is to audit patients perspectives routinely. Further investigations are needed to better define, validate, and understand constructs and processes identified in this study.
\end{abstract}

Keywords: bariatric surgery; pre-surgery evaluation; interpretative phenomenological analysis

\section{Introduction}

Bariatric surgery (BS) is an effective treatment for people who are morbidly obese [1] leading to significant weight loss, improvement in obesity-related conditions (e.g., Type-2 Diabetes), and reductions in mortality and demand on healthcare services [2-6]. BS is a major operation where the surgeon may use a variety of procedures to make changes to the digestive system, which can facilitate weight loss. There are different types of surgery, including the malabsorptive (biliopancreatic diversion and biliointestinal bypass), restrictive (adjustable gastric banding, vertical-banded gastroplasty, and sleeve gastrectomy), and a combination of both (gastric bypass and Roux-en-Y gastric bypass) [7]. Malabsorptive surgeries prevent the absorption of food, while the restrictive procedures aim to reduce the volume of food intake due to early satiety [8]. The surgery may also result in hormonal alterations [9] that can contribute to decreased appetite. It involves significant lifestyle changes and risks, including blood clots, infections, blocked gut, malnutrition, anaemia, and death, and does not guarantee weight loss [10]. BS is typically considered when nonsurgical weight loss interventions have failed, and obesity-related conditions are likely to improve [1]. In the National Health Service (NHS) in the UK, bariatric surgery candidates (BSCs) undergo a complex pre-surgery evaluation (PSE) on their readiness for surgery, 
involving a surgical, medical, dietetic, and psychological review. The PSE process has been considered to be particularly challenging, e.g., [11].

\subsection{Expectations of Bariatric Surgery}

An important aspect of the PSE is expectation management. Patients consider surgery as 'the miracle moment that will solve all life's problems' [12] (p. 1716), including regaining eating and weight control [12-18]. Some patients also perceive themselves as passive, or even powerless, participants in the surgery process and weight management [12,15], displaying little ability or willingness to implement behavioural and lifestyle changes themselves [19]. Unfortunately, many such perceptions or attitudes are not always detected, challenged, or modified adequately throughout the BS pathway, e.g., [19], despite the impact of patients' expectations on clinical outcome [20].

\subsection{Pre-Surgery Evaluation and Candidate Selection Process}

The PSE process is challenging, involving a multi-disciplinary review, education, expectations management, and post-operative planning (e.g., behavioural and lifestyle adaptations) [11]. No consensus exists regarding the function of the evaluation, the utility or objective of psychological testing, and the reasons for denial or delay [21,22]. Existing recommendations do not differentiate the roles within the multi-disciplinary team (MDT) and although some services aim to improve outcomes by identifying and addressing psychosocial challenges and risk factors, other services consider PSE as a platform to identify 'successful' candidates to avoid poor surgery outcomes (i.e., 'gatekeeping') [19\}. Health professionals (HP) carrying out pre-surgery assessments report being perceived, or actually controlling access to BS through 'gatekeeping' [21-24]. Although poor pre-surgery weight loss management or unmanaged psychiatric status/symptoms have been used to postpone or even deny surgery due to the limited resources available, the predictive utility of these on post-surgery outcomes remains contentious and they should not be considered in isolation during the PSE process [1,11,22,23,25-28]. Consequently, many BSCs express inadequate support and information, frustration over a lengthened process, and fear of being refused a highly valued and life-changing service; therefore, BSCs are typically very determined to show the commitment required [11,29].

Challenging experiences of accessing a limited but desired resource may influence perceptions and behaviours towards evaluative processes, e.g., [30]. BSCs may engage in impression management (IM) during PSE as a coping mechanism to present themselves as healthy [31-34]. Unfortunately, these individuals may not receive the support to adjust to the life changes surgery entails, leading to exacerbation of existing psychosocial distress and poor post-surgery outcomes, e.g., [35].

\subsection{Study Rationale, Aims, and Research Questions}

BSCs' perspectives and experiences of the PSE process have been overlooked in the literature. Service user perspective and involvement (SUPI) is perhaps particularly relevant during the PSE. SUPI in service delivery is an international and national agenda item [36-38]. SUPI is beneficial to service delivery, including improved information and accessibility, coordination of care, patient-HP relationship, identification of needs and preferences, and positive clinical outcomes [39-41]. Moreover, in the current context of the COVID-19 pandemic, where the British Obesity and Metabolic Surgery Society (BOMSS) [42] urged the backing of increased access to bariatric surgery, it will be essential that the complexity and life-long adjustment challenges of undergoing bariatric surgery are not undermined, as it may negatively affect surgery outcomes and postsurgery adjustments.

Accordingly, there is a clinical need to better understand patients' experiences and expectations of the PSE process within the NHS as it appears to be particularly challenging. This qualitative study explores the experiences and expectations of bariatric PSE amongst 
patients who have undergone BS using the interpretative phenomenological analysis (IPA). The study will aim to address the following research questions:

- What are participants' understanding and expectations of the bariatric PSE process?

- What are participants' experiences of the bariatric PSE process?

- What are participants' coping strategies for dealing with the bariatric PSE process?

\section{Materials and Methods}

\subsection{Design, Study Population, and Data Collection}

An interpretative phenomenological analysis (IPA) approach was used in this study. IPA is a psychological qualitative approach involving a comprehensive examination of the details of lived experience. More precisely, it is an in-depth interpretation of each participant's experience and the meaning which the experience holds for the individual. IPA is particularly useful for understanding under-researched phenomena or perspectives, and suitable for identifying and understanding meaningful subjective experiences or perspectives [43-45].

Four participants were recruited and interviewed from NHS BS support groups in London, UK through a convenience sampling and 'snowballing' method with the support of expert-by-experience. IPA recommends a purposive sampling (e.g., referrals or 'snowballing') to deliberately select participants based on their shared characteristics (i.e., homogenous sample), as individuals are recruited for their unique experiences and perspectives [43]. In this study, homogeneity was defined as those having undergone PSE and BS within the NHS in the UK. Furthermore, in qualitative studies, and IPA in particular, study samples are usually small to enable a very detailed and rich analysis, consistent with its commitment to idiography. For instance, IPA studies have been published with, for example, one, four, or nine participants, e.g., [46,47], and there are recent publications using IPA with similar sample sizes of four, e.g., [48], and five, e.g., [49] participants. Thus, qualitative studies are more concerned with 'study integrity' (e.g., creditability, transparency, consistency see [50]), and IPA studies are particularly concerned with 'depth of analysis' and 'richness of the individual cases', e.g., [43,47]. To demonstrate study integrity, the study has maintained consistency between aims (i.e., the exploration of unique experiences) and methodological approach (i.e., IPA) [43] as well as providing a rich and detailed analysis of each participant's experiences. Moreover, interpretations were advanced and validated through a rigorous process involving repetitive cross-checking of source material, and evaluation by the study supervisor and expert-by-experience. This process also ensured that arguments were coherent and logical. Finally, the report provides a carefully structured and detailed description of the research process stages, including tables and figures where appropriate (see below). Moreover, Smith et al. [43] highlighted that decisions regarding sample size need to be contextual and pragmatic to account for accessibility to the population and resources to recruit. It is notable that access to BS in the UK remains limited [4,51], reducing availability and access of possible samples. In addition, reaching and recruiting stigmatised groups (e.g., individuals who are obese or have undergone BS [52]) is challenging, even with the help of associated organisations (e.g., charities, clinics). This is particularly the case where responses cannot be categorically anonymous, (i.e., face-to-face interviews [53]).

No financial incentives were provided for participation, although travel costs were reimbursed (up to $£ 10$ ). The study received full ethical approval from the Psychology Department, Royal Holloway, University of London.

The inclusion criteria required participants to be English-speaking adults aged 18 years or above, who had undergone BS in the UK through the NHS and lived in the greater London area at the time of the study. Exclusion criteria constituted refusal of recording of the interview, surgery occurring more than 10 years ago, and diagnosis of DSM-V Axis I (dementia, schizophrenia, paranoid disorder, or abuse of alcohol and/or drugs) or Axis II disorders (personality disorder). These were identified through self-reports. See Table 1 for demographic data. 
Table 1. Demographic data.

\begin{tabular}{|c|c|c|c|c|c|c|c|c|c|c|c|}
\hline $\begin{array}{l}\text { Participant } \\
\text { (Pseudonym) }\end{array}$ & Gender & Age & $\begin{array}{c}\text { Marital } \\
\text { Status }\end{array}$ & Ethnicity & $\begin{array}{l}\text { Education } \\
\text { Level }\end{array}$ & $\begin{array}{l}\text { Currently in } \\
\text { Employment } \\
(\mathrm{Y} / \mathrm{N})\end{array}$ & $\begin{array}{c}\text { Hospital Name } \\
\text { (Pseudonym) }\end{array}$ & Type of BS & $\begin{array}{l}\text { Time } \\
\text { Since Post- } \\
\text { Surgery }\end{array}$ & $\begin{array}{l}\text { W/T Since } \\
\text { Referral }\end{array}$ & $\begin{array}{c}\text { Weight } \\
\text { Management }\end{array}$ \\
\hline George & Male & No info & No info & No info & No info & No info & Wallace Hospital & $\begin{array}{c}\text { No info } \\
\text { Gastric Banding } \\
\text { (private) }\end{array}$ & $2019 *$ & 48 months ** & No info \\
\hline Holly & Female & 51 & Married & White/Caucasian & $\begin{array}{c}\text { Master's } \\
\text { level }\end{array}$ & No & $\begin{array}{c}\text { Wallace/Stanford } \\
\text { Hospital }\end{array}$ & $\begin{array}{c}\text { Gastric Bypass } \\
\text { (private) } \\
\text { Sleeve } \\
\text { Gastrectomy } \\
\text { (NHS) }\end{array}$ & $\begin{array}{l}2012 \\
2013 \\
2016\end{array}$ & 12 months & No \\
\hline Sabina & Female & 29 & Single & $\begin{array}{c}\text { Black/African/ } \\
\text { Caribbean/Black } \\
\text { British }\end{array}$ & A-levels & No & $\begin{array}{l}\text { Hillsdale } \\
\text { Hospital }\end{array}$ & $\begin{array}{l}\text { Sleeve } \\
\text { Gastrectomy } \\
\text { (NHS) }\end{array}$ & 2019 & 48 months * & Yes \\
\hline Rachel & Female & 61 & Married & White/Caucasian & >A-levels & No & Wallace Hospital & $\begin{array}{c}\text { Gastric Bypass } \\
\text { (NHS) }\end{array}$ & 2018 & 15 months & Yes \\
\hline
\end{tabular}

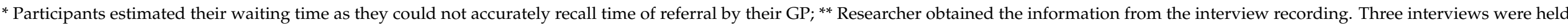
face-to-face, and one interview was held online. 
Information and consent sheets were emailed at least $24 \mathrm{~h}$ in advance of the interview and were provided on the day of interview.

\subsection{Data Analysis and Rigour}

Semi-structured interviews were conducted using an interview schedule to guide the process (Supplementary Material S1). The interviews lasted 38-58 min (mean: $48 \mathrm{~min}$, sd: 8). All interviews were audio-recorded, transcribed verbatim, and anonymised.

Data were analysed by the first study author and reviewed by the study supervisor (AR), expert-by-experience, and a peer who was familiar with IPA. The analysis procedure was consistent with IPA principles and broadly followed published guidelines $[43,47,54]$ as well as suggestions from the study supervisor.

The software program NVivo 11 facilitated data management. The analysis process was inductive and iterative.

The IPA first involved manual transcribing of the interview and close reading of the transcription multiple times while making initial notes of observations and reflections on the interview experience or thoughts of potential importance. This process commenced following the first interview to inform and develop subsequent interviews $[43,44,47,54]$. The second step involved exploring, evaluating, and working on the notes, transforming them to concise phrases ('emerging themes') that capture the essence of the original text. Finally, emerging themes were grouped or merged according to their conceptual similarities, creating superordinate themes. Some of the emerging themes were dropped if they were considered to have a weak evidential base (i.e., not supported by sufficient data from the transcript) or did not fit well with the overall structure of the participant's narrative. Notably, themes from the previous participant(s) were used to orient superordinate themes for subsequent participants, which helped to acknowledge new idiographic issues emerging while also discerning repeating patterns [43].

\subsection{Service User Involvement}

One expert-by-experience, who had undergone PSE and BS in the NHS, was recruited to provide consultation throughout the research process. They were actively involved in the interview schedule development, recruitment, analysis, and dissemination.

\section{Analysis}

An analysis revealed three superordinate, and eleven subordinate themes (Table 2, Supplementary Table S1). The three superordinate themes are closely linked through feelings of loss of control and attempts to regain or maintain it.

Table 2. Master Table of Themes.

\begin{tabular}{ccc}
\hline Superordinate Themes & Subordinate Themes & Number of Transcripts Contributing to Theme \\
\hline \multirow{2}{*}{ PSE was challenging but } & A long but necessary PSE & 4 \\
essential & Scrutiny and suitability & 4 \\
& 'Psych' as a wall & 4 \\
& Psychological coping strategies & 3 \\
Coping processes to deal & Doing your own research & 4 \\
with the PSE & Support systems & 4 \\
& Past experiences influencing current perspectives & 4 \\
Staff and service & Self-perception & 3 \\
evaluation & A tailored PSE & 4 \\
\hline
\end{tabular}




\subsection{Superordinate Theme One-'PSE Was Challenging but Essential'}

Most participants had conflicting feelings about the PSE process. PSE was experienced as challenging, which reflected the length, uncertainty, and difficulty of receiving approval for surgery. Participants felt that they were intensely scrutinised whilst perceiving the 'psych' as a gatekeeper to surgery, which led to the need to prove or defend suitability for surgery. Equally, PSE provided valuable time for self-reflection and information gathering, which was considered to be essential for preparing for the surgery and a successful postsurgery adjustment.

3.1.1. A Long but Necessary PSE: 'It Could Be Shorter, but It Gives You Time to Reflect ... '

Most participants expected or experienced a lengthy but essential process to make sure they were suitable and prepared for the surgery procedure and post-surgery life. The length allowed time for research and self-reflection which may have facilitated the informed decision-making process. The conflicting perspective of valuing time to make an informed decision whilst also feeling frustrated with the prolonged process is illustrated in the two extracts below:

'To put it in perspective, a good friend of mine she's gone and have the surgery done privately ... and the difference is hers was rushed, she made the decision within a week. [... ] although mine's been longer than normal because we've had hiccups along the way ... I think that were it longer process it allows you to absorb what you going to embark on and what you're going to have done.' -George

'[I was told] I've been taken off the whole system, [ . . ] when I last saw the surgeon, I got an $O K,[\ldots]$. So, it was waste of travel going down there, and then have to wait months to see her again [ ... ], it was like a stressful time for me, and, I was like comfort eater, so I had put on a lot of weight during that period [ ... ]. I was really depressed because I just thought didn't know I was coming or going, I'd waited so long, I was just thinking, this whole process is pointless because I'm waiting like 3 years at the time [... ] and I don't think I'll be having this surgery' —Sabina

The process was felt to be fraught with errors that prolonged the evaluation and had a significant emotional impact related to a sense of loss of control. For Sabina, the prolonged process signified a sense of being undervalued ('taken off the system') and uncertainty ('didn't know I was coming or going') of surgery recommendation, leading to a vicious cycle of stress and frustrations ('waste of travel'), emotional eating and weight gain, low mood, and hopelessness ('I don't think I'll be having this surgery').

\subsubsection{Scrutiny and Suitability: 'They Properly Grilled $\mathrm{Me}^{\prime}$}

There was a perception that poor weight management or mental health were contraindications for surgery, resulting in experiences of threatening scrutiny of weight and psychiatric self-management, as indicated in the evocative extracts below.

'there was an idea that you couldn't put on weight ... that if you were gaining weight then that could go against you so it was ... [ ... ] and that was a fear' -George

'I was expecting to go and be grilled on what you eating which is why I had my Slimming World book proof, 'this is what I'm eating, I keep food diaries' and they were like, 'have you been honest?' and I was like, 'yes because you can see on that day I ate like a horse' -George

'I would have to prove I can lose weight and keep off for a certain amount of time ... [ ... ] aaand work out ... [ . . . I I was very stressed because I didn't know how I was going to keep my weight off' - Sabina

'I was feeling a lot down, because again I was thinking I'm not going to get the surgery. And then, that spirals into putting on weight, so yeah it did affect my life a lot.' - Sabina 
Participants reported considerable anxiety at the possibility of having the surgery rejected as well as pressure, or even desperation, to demonstrate one's suitability for surgery, including the use of a riskier negative IM strategy. This appears to have facilitated the aforementioned (see first subordinate theme) vicious cycle of distress and anxiety, emotional eating and weight gain, low mood, and hopelessness.

Feelings towards this scrutiny were, however, conflicting and dynamic. On the one hand, there were feelings of anger ('cross'), emptiness, ('what's left?'), desperation ('last chance to live') and unwilling conformity ('toes the line'), and on the other hand, there were feelings of hope ('light at end of the tunnel') and eventual insight of the necessity of the evaluation process to success.

'I was a bit cross [at the time] cuz they were taking something else away from me [food, alcohol ... . . And I had to go through this whole thing about what's left. [ ... I I still went in for the operation cuz it was last chance to live. [ . . . There was the light at the end of the tunnel, so I did toe the line. [ . . . I've [now] got a positive attitude towards [PSE] because my life has changed massively.' - Rachel

\subsection{3. 'Psych' as a Wall: They Can Make-or-Break Surgery}

The psychological assessment was considered to be the most important aspect of the PSE process, as it could influence the decision-making process of surgery approval ('makeor-break'). Participants also considered the 'psych' to deliberately seek contraindications to surgery, resulting in the psychological assessment to be perceived as an obstacle ('she must be a wall') to surgery. This expectation and experience led to worries about revealing surgery contraindications and surgery rejection, and defensiveness and IM strategies, such as information regulation and self-monitoring, as participants felt unable to trust and be open with the 'psych'. Note that 'psych' was used synonymously to refer to both 'psychologist' and 'psychiatrist', which may be related to the ambiguous role that 'psych' has in this process [19].

'I was told that the psychiatrist ... that was quite an important meeting because they would kind of the ones that would also sign off to say yes [ . . ]. As I said I think I was just worried that that was the ['psych'] appointment that could make-or-break it.' -George

'Seeing the psychiatrist, I was really stressed, and really down because I was thinking, 'what is she going to say, she must be a wall ... refuse me for surgery. [ ... I I think just kind of went there knowing ... what I was going say and what I wasn't going to say [because of] fear of her saying no' - Sabina

\subsection{Superordinate Theme Two: 'Coping Processes to Deal with the PSE'}

This superordinate theme reflected external and internal strategies to deal with the PSE process, and often reflected attempts to increase, regain, or maintain a sense of control in the context of the challenges experienced throughout the PSE.

\subsubsection{Psychological Coping Strategies: 'Is It a Case of Going through the Motions?'}

This subordinate theme reflected participants approach towards the PSE process. Although participants' narratives suggested a sense of loss of control due to needing to comply with service expectations and conditions, paradoxically, they also appeared to be engaging in coping strategies, mainly through conformity without conviction, to recover some sense of control by increasing their chances of approval.

'it was a case of going through the motions on ... going through admin on that team [ . . but] If I had to go through the psychologist there, it would been a lip-service/me getting very angry $[\ldots]^{\prime}$ - Holly

'I toed the line because I knew if I stepped out of that line, I would end up being at back of the queue. [ ... I I felt like I'd been singled out to jump through these hoops, and not everybody else [... ]. And I passed all the hoops that I had to jump through - Rachel 
'I think that if I were had went in there still saying that I was gonna get to a size 10, they would've refused me' —Sabina

\subsubsection{Doing Your Own Research: 'Or You Won't Be Successful'}

The importance of conducting one's own research on different aspects of the BS process was strongly endorsed, as it was thought to be necessary for a successful outcome and to facilitate agency and control, particularly over their health. Notably, participants felt that the information from HPs could be incorrect or insufficient for an informed decision. This is well summarised in Holly's comment.

'I don't think they're going to have as much success as the people that do the research, their own research for their own questions, and go into it with their eyes wide open ... [... I I also think each person needs to get it sorted within enough research. I think we need to take control of our destiny and not be led by doctors who think they're very clever.

[... I I don't think the information that I hear from [HPS] is adequate to make a decision' -Holly

It is possible that attitudes towards active involvement in the PSE process through information gathering may reflect the importance of choice and shared decision-making to maintain or facilitate a sense of control over health. Conversely, it may also reflect a perception of inaccessibility of information from HPs across the tiers at best, or a sense of distrust at worst. Indeed, the main source of information, particularly practical, on the PSE process was the internet and support groups.

'but yeah it was definitely the support group, it was like, I've got this appointment coming up, what should I expect? what question do they going to ask? how long is the appointment going to last? things like that' -George

\subsubsection{Support Systems: 'You're Kinda on Your Own without a Support Network'}

This subordinate theme reflected the sources of support that participants described as important in relation to the PSE. A supportive HP was not only reassuring but also facilitated the PSE process.

'The consultants ... I got what I eventually expected [i.e., standards of care], which was a knowledgeable person would listen to my individual concerns and ... fight my corner for me' - Holly

Access to formal psychological support was also highlighted.

'[The psychological evaluation] was a one-off evaluation [ . . . ] so I had to do something myself to make sure that I will be okay after surgery' —Sabina

'it doesn't matter if you don't get to the crux of why you overeat, operation or not operation, that is still gonna be there. And you'll still gonna want it. And if you can't have [food] when you really want it that's gonna add you more problems than before, so that has to all be straightened out first.' - Rachel

These quotes suggest a recognition that surgery does not cure obesity and concerns of weight management persist post-surgery. Psychological support may represent a safety net to ensure that the underlying issue of obesity (the 'crux') is addressed ('make sure that I will be okay after surgery'). Perhaps, this reflects a 'trigger for change' attitude towards surgery [19].

The most essential source of support, however, was informal support, captured in George's succinct comment.

So, if you don't have a support network at home ... you're kind of on your own' - George

The support group was considered essential because the shared experience of the surgery process facilitated empathy. 
'if they [family and friends] haven't gone through it ... they don't appreciate or understand what you're going through. Whereas people at the support group do. [ ... I I mean even now post-surgery that support group is a mechanism' -George

\subsubsection{Past Experiences Influencing Current Perspectives}

Previous negative experiences of health services and HPs highlighted emotional vulnerabilities (e.g., fear of negative evaluation) and guided expectations and approaches to the PSE process.

'medical professionals that I've seen over the years have been very quick to judge that I am the size I am because I'm lazy, I eat too much, and things like that [ . . . I think it's being prejudged ... [ . . . ] it was having those prejudgments already made.' -George

'I think it's just through a life of some particular hard knocks that .. . [ . . I some incidents happened when I was at work not long before I had the surgery ... made me into a 'don't mess with me' type of the person. [ . . . ]' - Holly

'because I had lost weight before but I still was very depressed, so I knew that I had to [seek psychological therapy]. So I prepared in that way' —Sabina

George appeared to anticipate judgement, which perhaps allowed him to prepare and buffer against negative evaluations he had experienced in the past. Holly explained that her difficult life experiences allowed her to be more assertive. Sabina had acknowledged the relationship between her obesity and depression following previous weight loss; therefore, she prepared by seeking structured psychological support.

\subsubsection{Self-Perception: 'Psychological Functioning and the Need for Psychological Input'}

The need for psychological input was based on perceptions of its purpose and selfperception of one's own psychological functioning. A unidimensional view of the purpose of psychological input (e.g., for people who 'comfort eat' or are 'blubbery') and a selfperception of strong psychological functioning, resulted in a belief that it was unnecessary.

'I ... am of the opinion I'm fairly well enough to stand on my own two feet, and don't need my head examined. So while some people are blubbery and use food as a tool, I did, started BS to try and buy myself time for my diabetes [... ] So, the whole morals of why you comfort eat and all the rest of it, I did not think applied to me' - Holly

Conversely, a more dynamic perception of psychological functioning in relation to post-surgery adjustment resulted in acknowledging and valuing the PSE process and receiving psychological input.

'after when I saw that psychiatrist I said to her even in that meeting I'm going to see someone [referring to a mental-HP] on a regular basis because I knew that was paramount for $m e^{\prime}$ - Sabina

'But I think a lot of it also stems from me being so unhappy about the size I am. Because now, I'm so much happier person. [ . . . ]. I understand myself a lot more going through this process.' - Rachel

\subsection{Superordinate Theme Three: 'Staff and Service Evaluation'}

This superordinate theme is related to a sophisticated evaluation process of the HPs and service. It reflected participants' capacity to think about their own and other bariatric patients' needs in the context of advanced knowledge of BS and its impact. This feedback process also appeared to be attempts to exert a form of control over the PSE in response to the challenges experienced.

\subsubsection{A Tailored PSE: 'Everybody Is Different'}

Most participants acknowledged individual differences, needs and circumstances, and therefore preferred a tailored PSE approach. 
Some participants recognised that surgery could have unpredictable effects, requiring major lifestyle changes unique to the individual in relation to life-stage. These factors were considered to influence the decision to have surgery, and was considered as an essential topic to be discussed in the evaluation process. Rachel and George's extract capture much of this.

'everybody is different. You also learn along the way that ... this operation has an effect on an individual person that is not known until you've had the operation. [ ... ] as I was an older person, I feel that that wasn't such a big decision as a person saying in the $30 \mathrm{~s}$, because that's a hell of a lot longer, you have to have these life changing things for than I do' - Rachel

"And again I think that need to be looked at an early stage because it is a lifestyle change' -George

As Holly expressed that the psychological assessment was less relevant to her, she endorsed the idea that PSE should be tailored to each individual need.

'There needs to be a fast track for people like me and that are very strong emotionally and is clear and logical' - Holly

Holly's pithy quote suggests a motivation to influence service delivery, which may reflect a form of exerting control over the PSE process by suggesting service improvements.

\subsubsection{Level of Information}

Participants were unsatisfied with the level of information that they received from the service about the PSE process, particularly the psychological assessment. This had a considerable emotional impact on most participants as they felt unprepared to cope with the process.

'I think that they need to have like a booklet or something, or even if they did like a video, and it's on their public page, even if its private or NHS and it's on their page to explain each tier and what they expect of the patient, so people aren't in the dark, and they don't know what the next steps are and what is going to happen after surgery ... ' - Sabina

'I think I would've coped further in the beginning, [ . . ], if I'd have been given a schedule. [ ... ] I was working blind I didn't know any of that. If I would've know that ... [long waiting] I would have been a bit more prepared for that. I found all that a little bit shocking [laughing]' -Rachel

Sabina felt lost in the process ('so people aren't in the dark') and Rachel's laugh after describing the lack of information as 'shocking' perhaps signifies that she thought this was unbelievable, as their anxieties could have been buffered by additional information. Consequently, there was a greater reliance on obtaining practical information from people who had undergone the process.

'on the Facebook group [for the Support group] there's people now as I said that are questioning what to expect and those of us that had it done we then go on and put, 'this is our experience, what they asked, what they're likely to cover' - George

Rachel, however, was generally positively surprised about the information given on the surgery and post-surgery processes, making her feel more confident.

'I didn't expect to get so much information, like meetings about pre-op, and after the op, so I could be, once I got to that stage, I was mentally much more prepared and ready for my operation' - Rachel

\subsubsection{Praise and Criticism of the Service}

Participants expressed dissatisfaction towards the HPs actions and aspects of the service delivery. Participants described poor rapport and trust in the HPs due to perceptions of lack of understanding and empathy. Some participants felt that the HPs worked against, 
rather than alongside their goals and expectations. Sabina's elaborate comment captures the poor client-HP relationship, which appears to foster a sense of an 'us vs. them' attitude during the PSE, resulting in a struggle of 'one-upmanship'.

'I kind of feel the dietitian, she wasn't sympathetic [ ... ] she kept telling me, you're not going to meet this goal and you'll never get there, and so there is something in my notes that says, this patient thinks that she will get to a UK dress size 10, but I've explained to her that this is unrealistic, and then, that went to [the MDT]. So, [the 'psych'] had discussed it with me as well, saying, do you still think that you're going to get to a size 10, this is unrealistic [ . . . B But she was wrong because I've lost more than that!' - Sabina

However, participants also felt gratitude towards the HPs and services and an obligation to reciprocate.

'I mean I feel like I owe lot to Wallace because obviously what they've given me [ . . ] so by giving something back, I make an effort to go to the support groups [... ] to kind of show them and to say thank you to Wallace's cuz I appreciate what they've done for me' - George

'Well I think my role, is why I go to the support group, is to help others' -Rachel

It is notable that participants felt a sense of loyalty and gratitude towards the service despite the negative impact the PSE had on their well-being and self-value (e.g., distress, being forgotten). It is possible that this conflicting feeling may reflect a need to increase control through involvement in influencing and improving service delivery; although, the value surgery held for participants (e.g., 'last chance to live') is also likely to be an important contributor.

\section{Discussion}

\subsection{Summary of Main Findings}

This study explored the experiences of the bariatric PSE process in the NHS using IPA. The analysis revealed three interlinked superordinate and eleven subordinate themes (Table 2). Central to the experience was the first superordinate theme, 'PSE was challenging but essential'. The PSE was experienced to be lengthy and surgery approval difficult and uncertain. Conversely, the PSE provided time for self-reflection and information gathering considered as essential for surgery preparation and outcome. The second superordinate theme, 'Coping processes to deal with the PSE', reflected strategies in navigating the PSE process to increase chances of surgery approval. The third superordinate theme consisted of evaluation of the HPs and service, and suggested a motivation to improve the bariatric service. Permeating or underlying these themes were feelings of loss of control, attempts to regain control, and attempts to maintain control (see Figure 1).

\subsection{Strengths and Limitations}

The main strength of the study is that it addressed a clinically meaningful area that had been overlooked in the literature. It provided a rich and detailed representation of the PSE experience from the candidate's perspective and identified previously unrecognised constructs and processes.

Several limitations of the study that may have constrained the scope of the research need consideration. The sample size was small, even for an IPA, although the study attempted to provide a detailed narrative of the study participants' experiences, consistent with the idiographic principle of the IPA. There was some heterogeneity within the sample which may have affected experience, perceptions, and recollection of the PSE, such as service received, surgery offered, and time since post-surgery. There was also some minor demographic information missing from one participant. Despite these limitations, the sample size is acceptable $(n=4)$, e.g., [43,44,46-49] and it is evident from the resulting themes that commonalities existed across narratives, providing valuable insight into the experiences of BSCs. 


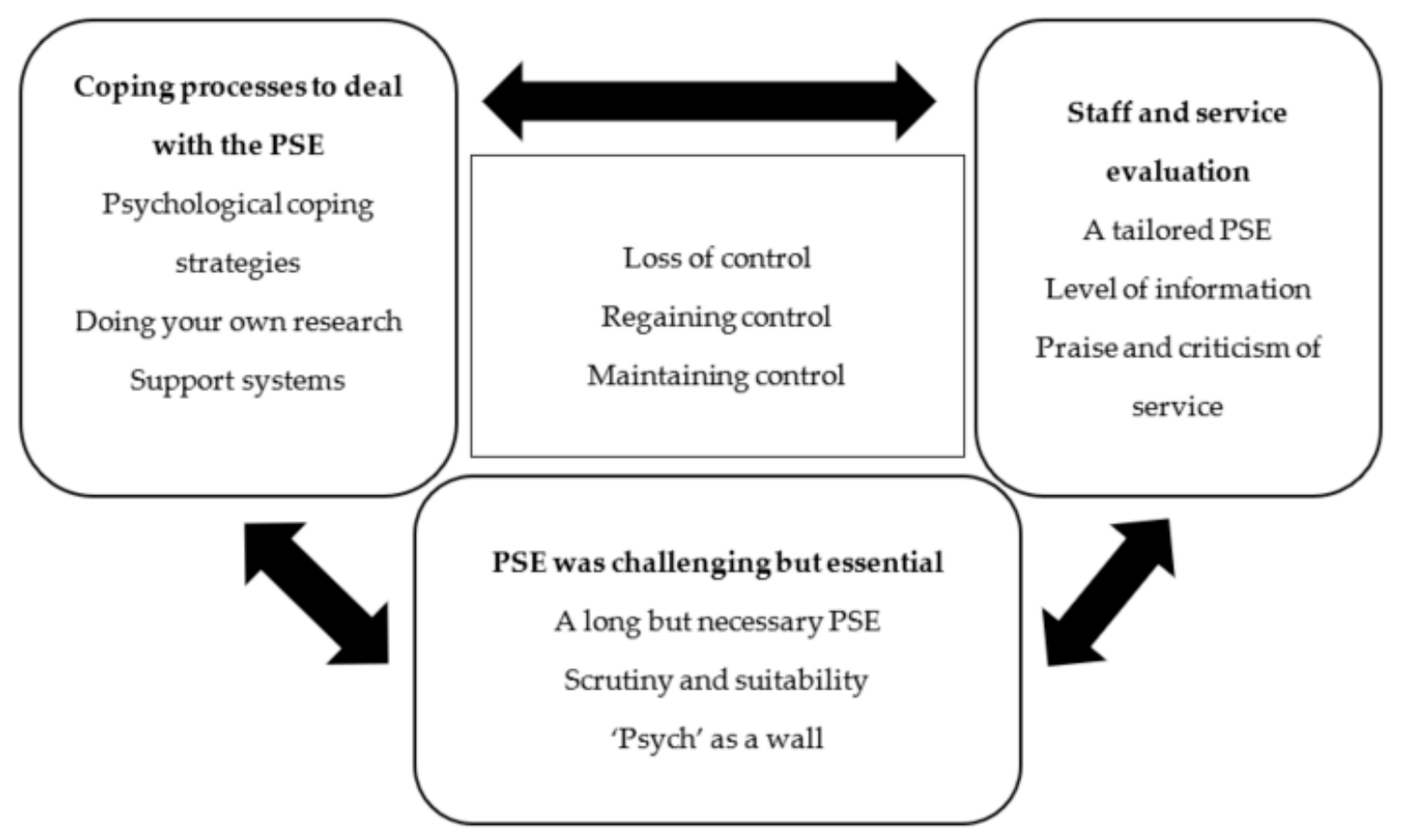

Figure 1. Visual representation of the themes.

\subsection{Themes within the Wider Context}

The themes presented in this study overlap with the challenges and perceptions reported within the extant literature on bariatric service delivery and the PSE, e.g., [11]. There is a recognition that the function of the PSE, and particularly the psychological evaluation, remains challenging and ambiguous, wherein contentious contraindications are used as 'gatekeeping prioritisation' in some services [11,21-25,28,55]. Concurrently, there is an acknowledgement that there is variability in patients' perceptions of level of support and information experienced which has been linked to a sense of loss of control, e.g., $[11,17,29]$. More specifically, previous studies suggested that control is an important concept for patients who have undergone BS, and that paradoxically, imposed control and limited choice can in some instances result in a renewed sense of control [17]. Other studies have also highlighted some frustration in the way in which access to referral to BS were discussed with their primary care provider, where most patients had to raise the issue themselves and some interpreted this as evidence of implicit rationing $[21,29,56]$. This particular study also shed light on the extent to which patients were generally unprepared for the further referral 'gatekeeping' or barriers they encountered in secondary care [21,29].

The study analysis also presented a nuanced extension to the extant literature. Firstly, it highlighted participants' conflicting feelings towards the PSE. The PSE was characterised by a poor patient-HP relationship and described as lengthy and uncertain, leading to a sense of loss of control that had a considerable negative impact on psychological and physiological health. Indeed, the high prevalence of psychopathology, including depression, anxiety, eating disorders, and substance abuse is well documented among bariatric surgery candidates, e.g., [33,34]. It is possible that the PSE process experienced by the participants of this study may further exacerbate these symptoms for some candidates.

Conversely, the lengthy process provided time for reflection and informed decisionmaking considered necessary for a successful surgery outcome. Secondly, the analysis discovered several external and internal coping processes that helped participants regain, maintain, or facilitate a sense of control when navigating the challenges of the PSE. These included positive and negative IM, psychological coping style, agency and responsibility, help-seeking, and utilisation of previous experience to guide expectations. Finally, the study highlighted participants' advanced understanding of BS and its unpredictable conse- 
quences, and motivation to improve service delivery, particularly through involvement in the support group. This contrasts with the extant literature suggesting that many patients hold unrealistic expectations and poor knowledge, e.g., [12,15].

In this study, most participants' experiences and perceptions of the PSE appear to represent a service model that aims to identify 'successful' surgery candidates through identification of contraindications to surgery, rather than identifying support needed to increase post-surgery success. This is consistent with findings in the extant literature suggesting that the PSE in some services is influenced by the rationing culture within the NHS $[5,21,22,56]$ due to a BS demand-supply discrepancy [4,51,57]. This model reflects an unhelpful 'paternalistic' approach to evaluation that may undermine the patient-HP relationship [58,59]. Specifically, when patients are active agents in managing their health, as with the study participants, a paternalistic approach may reduce choice and foster a sense of loss of autonomy, poor communication, and distrust $[17,60,61]$. This may reduce overall service satisfaction, and hinder identification of needs (e.g., non-adherence to diet) and implementation of appropriate support [62]. Conversely, a patient-centred approach to the PSE process can improve patient outcomes, particularly when patients are actively involved in their treatment $[63,64]$. This approach appears to be consistent with the preferences of the study participants who showed motivations to influence service delivery through constructive feedback and support group contributions. It is also in line with the national agenda promoting SUPI and stepped care model proposed by Ogden et al. [65] advocating a tailored psychological input based on patient complexity and need.

The importance of a tailored patient-centred approach to the PSE is particularly relevant in the context of the COVID-19 pandemic. The government has acknowledged the links between ill health strategy [66,67], as obesity appears to be highly correlated with severe COVID-19 symptoms and death rates [68]. Consequently, the BOMSS [39] suggested that bariatric surgery can provide a 'quick-fix' against the suffering and death caused by COVID-19. However, the complexity and life-long adjustment challenges of bariatric surgery cannot be undermined, as it may negatively affect surgery outcomes and post-surgery adjustment, e.g., $[13,14,16]$. In this context, the PSE has a central role in identifying needs and supporting individuals to achieve successful outcomes.

\subsection{Future Research and Clinical Implication}

The present study presents an opportunity to further expand the understanding of the BS process and PSE. Future research needs to build on the current qualitative study using other methodologies, including mixed and quantitative (e.g., cross-sectional), to further elaborate the validity and reliability of the processes and constructs identified. Specifically, future studies can investigate the nature and prevalence of emotional distress, coping strategies, including negative IM, and the patient-HP relationship and their relationship to post-surgery outcome and adjustment. Moreover, the current study may hopefully encourage academics and clinicians working in the bariatric field to consider ways to involve and collaborate with service users in influencing the service delivery in a way that is appropriate and beneficial. A starting point for services is perhaps to audit patients' perspective using the findings from this study as a rough guiding template. Such endeavours may counter the unhelpful 'paternalistic' approach, and instead facilitate empowerment, a sense of control, and a patient-professional relationship [17,61]. Overall, these recommendations can lead towards a more patient-centred service delivery wherein the PSE is considered a constructive opportunity to identify psychosocial challenges and risk factors, e.g., [22,34], during the PSE and provide appropriate support throughout the pathway to improve surgery outcomes [22].

\section{Conclusions}

This study explored the experiences of the bariatric PSE in the NHS using the IPA methodology. Three main themes emerged from our interviews with BSCs, revealing some challenges in service delivery that impacted participants' well-being. It also revealed 
some coping strategies used to navigate this difficult process and a motivation to be more involved in service delivery. Further investigations are needed to better define, validate, and understand these constructs. Results from this study could be used by both healthcare providers and researchers to involve patients in service delivery thereby facilitating a patient-centred approach.

Supplementary Materials: The following are available online at https://www.mdpi.com/article/10 .3390 / surgeries2020021/s1. Supplementary Material S1, Interview Schedule; Table S1. Extracts for final themes.

Author Contributions: Conceptualization, K.S. and A.R.; methodology, K.S.; software, K.S.; validation, K.S. and A.R.; formal analysis, K.S.; investigation, K.S.; resources, K.S.; data curation, K.S.; writing-original draft preparation, K.S.; writing—review and editing, K.S. and A.R.; supervision, A.R.; project administration, K.S. All authors have read and agreed to the published version of the manuscript.

Funding: This research received no external funding.

Institutional Review Board Statement: The study was conducted according to the guidelines of the Declaration of Helsinki, and approved by the Institutional Review Board (or Ethics Committee) of Royal Holloway, University of London (protocol code 1655, 29 July 2019), Egham Hill, Egham TW20 0EX, United Kingdom.

Informed Consent Statement: Informed consent was obtained from all subjects involved in the study.

Data Availability Statement: Transcripts and the Nvivo analytic process are available from the authors upon request.

Acknowledgments: Thank you to Nicky Crome, the expert-by-experience for their valuable consultation, reflections, and thoughts about the study. Thank you to the participants of this study-this study would not have been possible without them. Like them, I hope that this thesis will come to benefit other bariatric candidates that are in the position they have been in.

Conflicts of Interest: The authors declare no conflict of interest.

\section{References}

1. National Institute for Care and Excellence. Obesity: Identification, Assessment and Management (Publication No. CG189). 2014. Available online: https:/ / www.nice.org.uk/guidance/cg189 (accessed on 13 May 2021).

2. Chang, S.-H.; Stoll, C.R.T.; Song, J.; Varela, J.E.; Eagon, C.J. Colditz, G.A. The Effectiveness and Risks of Bariatric Surgery: An Updated Systematic Review and Meta-analysis, 2003-2012. JAMA Surg. 2014, 149, 275. [CrossRef]

3. Colquitt, J.L.; Picot, J.; Loveman, E.; Clegg, A.J. Surgery for obesity. In Cochrane Database of Systematic Reviews; The Cochrane Collaboration, Ed.; John Wiley \& Sons, Ltd.: Hoboken, NJ, USA, 2009; p. CD003641. [CrossRef]

4. Gulliford, M.C.; Charlton, J.; Booth, H.P.; Fildes, A.; Khan, O.; Reddy, M.; Ashworth, M.; Littlejohns, P.; Prevost, A.T.; Rudisill, C. Costs and outcomes of increasing access to bariatric surgery for obesity: Cohort study and cost-effectiveness analysis using electronic health records. Health Serv. Deliv. Res. 2016, 4, 1-120. [CrossRef] [PubMed]

5. National Bariatric Surgery Registry Data Committee (NBCR). The United Kingdom National Bariatric Surgery Registry of the British Obesity and Metabolic Surgery Society: Second Registry Report; Dendrite Clinical Systems Ltd.: Reading, UK, 2014.

6. Sjöström, L.; Lindroos, A.K.; Peltonen, M.; Torgerson, J.; Bouchard, C.; Carlsson, B.; Dahlgren, S.; Larsson, B.; Narbro, K.; Sjöström, C.D.; et al. Lifestyle, diabetes, and cardiovascular risk factors 10 years after bariatric surgery. N. Engl. J. Med. 2004, 351, 2683-2693. [CrossRef]

7. Buchwald, H.; Oien, D.M. Metabolic/bariatric surgery Worldwide 2008. Obes. Surg. 2009, 19, 1605-1611. [CrossRef] [PubMed]

8. Keidar, A.; Szold, A.; Carmon, E.; Blanc, A.; Abu-Abeid, S. Band slippage after laparoscopic adjustable gastric banding: Etiology and treatment. Surg. Endosc. 2005, 19, 262-267. [CrossRef] [PubMed]

9. Dimitriadis, G.K.; Randeva, M.S.; Miras, A.D. Potential Hormone Mechanisms of Bariatric Surgery. Curr. Obes. Rep. 2017, 6, 253-265. [CrossRef]

10. Sarwer, D.B.; Wadden, T.A.; Fabricatore, A.N. Psychosocial and Behavioral Aspects of Bariatric Surgery. Obes. Res. 2005, 13, 639-648. [CrossRef]

11. Neff, K.; Olbers, T.; le Roux, C. Bariatric surgery: The challenges with candidate selection, individualizing treatment and clinical outcomes. BMC Med. 2013, 11, 8. [CrossRef]

12. da Silva, S.S.P.; da Costa Maia, Â. Obesity and Treatment Meanings in Bariatric Surgery Candidates: A Qualitative Study. Obes. Surg. 2012, 22, 1714-1722. [CrossRef] [PubMed] 
13. Bauchowitz, A.; Azarbad, L.; Day, K.; Gonder-Frederick, L. Evaluation of expectations and knowledge in bariatric surgery patients. Surg. Obes. Relat. Dis. 2007, 3, 554-558. [CrossRef] [PubMed]

14. Bauchowitz, A.U.; Gonder-Frederick, L.A.; Olbrisch, M.-E.; Azarbad, L.; Ryee, M.-Y.; Woodson, M.; Miller, A.; Schirmer, B. Psychosocial Evaluation of Bariatric Surgery Candidates: A Survey of Present Practices. Psychosom. Med. $2005,67,825-832$. [CrossRef] [PubMed]

15. Engström, M.; Wiklund, M.; Olsén, M.F.; Lönroth, H.; Forsberg, A. The Meaning of Awaiting Bariatric Surgery Due to Morbid Obesity. Open Nurs. J. 2011, 5, 1-8. [CrossRef] [PubMed]

16. Kaly, P.; Orellana, S.; Torrella, T.; Takagishi, C.; Saff-Koche, L.; Murr, M.M. Unrealistic weight loss expectations in candidates for bariatric surgery. Surg. Obes. Relat. Dis. 2008, 4, 6-10. [CrossRef] [PubMed]

17. Ogden, J.; Clementi, C.; Aylwin, S. The impact of obesity surgery and the paradox of control: A qualitative study. Psychol. Health 2006, 21, 273-293. [CrossRef]

18. Wysoker, A. The Lived Experience of Choosing Bariatric Surgery to Lose Weight. J. Am. Psychiatr. Nurses Assoc. 2005, 11, 26-34. [CrossRef]

19. Homer, C.V.; Tod, A.M.; Thompson, A.R.; Allmark, P.; Goyder, E. Expectations and patients' experiences of obesity prior to bariatric surgery: A qualitative study. BMJ Open 2016, 6, e009389. [CrossRef]

20. Fischer, L.; Nickel, F.; Sander, J.; Ernst, A.; Bruckner, T.; Herbig, B.; Büchler, M.W.; Müller-Stich, B.P.; Sandbu, R. Patient expectations of bariatric surgery are gender specific-A prospective, multicenter cohort study. Surg. Obes. Relat. Dis. 2014, 10, 516-523. [CrossRef]

21. Owen-Smith, A.; Donovan, J.; Coast, J. How clinical rationing works in practice: A case study of morbid obesity surgery. Soc. Sci. Med. 2015, 147, 288-295. [CrossRef]

22. Ratcliffe, D.; Ali, R.; Ellison, N.; Khatun, M.; Poole, J.; Coffey, C. Bariatric psychology in the UK National Health Service: Input across the patient pathway. BMC Obes. 2014, 1, 20. [CrossRef]

23. Fabricatore, A.; Crerand, C.; Wadden, T.; Sarwer, D.; Krasucki, J. How Do Mental Health Professionals Evaluate Candidates for Bariatric Surgery? Survey Results. Obes. Surg. 2006, 16, 567-573. [CrossRef]

24. Glinski, J.; Wetzler, S.; Goodman, E. The Psychology of Gastric Bypass Surgery. Obes. Surg. 2001, 11, 581-588. [CrossRef]

25. Collazo-Clavell, M.L.; Clark, M.M.; McAlpine, D.E.; Jensen, M.D. Assessment and Preparation of Patients for Bariatric Surgery. Mayo Clin. Proc. 2006, 81, S11-S17. [CrossRef]

26. Livhits, M.; Mercado, C.; Yermilov, I.; Parikh, J.A.; Dutson, E.; Mehran, A.; Ko, C.Y.; Gibbons, M.M. Preoperative Predictors of Weight Loss Following Bariatric Surgery: Systematic Review. Obes. Surg. 2012, 22, 70-89. [CrossRef]

27. Pull, C.B. Current psychological assessment practices in obesity surgery programs: What to assess and why? Curr. Opin. Psychiatry 2010, 23, 30-36. [CrossRef] [PubMed]

28. Wadden, T.A.; Sarwer, D.B.; Fabricatore, A.N.; Jones, L.; Stack, R.; Williams, N.S. Psychosocial and Behavioral Status of Patients Undergoing Bariatric Surgery: What to Expect Before and After Surgery. Med. Clin. N. Am. 2007, 91, 451-469. [CrossRef] [PubMed]

29. Owen-Smith, A.; Donovan, J.; Coast, J. Experiences of accessing obesity surgery on the NHS: A qualitative study. J. Public Health 2016. [CrossRef]

30. Leary, M.R.; Kowalski, R.M. Impression Management: A Literature Review and Two-Component Model. Psychol. Bull. 1990, 107, 34-47. [CrossRef]

31. Ambwani, S.; Boeka, A.G.; Brown, J.D.; Byrne, T.K.; Budak, A.R.; Sarwer, D.B.; Fabricatore, A.N.; Morey, L.C.; O’Neil, P.M. Socially desirable responding by bariatric surgery candidates during psychological assessment. Surg. Obes. Relat. Dis. 2013, 9, $300-305$. [CrossRef] [PubMed]

32. Fabricatore, A.N.; Sarwer, D.B.; Combs, C.J.; Krasucki, J.L. Impression management or real change? Reports of depressive symptoms before and after the preoperative psychological evaluation for bariatric surgery. Obes. Surg. 2007, 7, 1213-1219. [CrossRef]

33. Heinberg, L.J. The Role of Psychological Testing for Bariatric/Metabolic Surgery Candidates. Bariatric Times Online Editor. Available online: https://bariatrictimes.com/the-role-of-psychological-testing-for-bariatricmetabolic-surgery-candidates/ (accessed on 13 May 2021).

34. Rosik, C.H. Psychiatric Symptoms among Prospective Bariatric Surgery Patients: Rates of Prevalence and their Relation to Social Desirability, Pursuit of Surgery, and Follow-Up Attendance. Obes. Surg. 2005, 15, 677-683. [CrossRef]

35. Heinberg, L.J.; Marek, R.; Haskins, I.N.; Bucak, E.; Nor Hanipah, Z.; Brethauer, S. 30-day readmission following weight loss surgery: Can psychological factors predict nonspecific indications for readmission? Surg. Obes. Relat. Dis. 2017, 13, 1376-1381. [CrossRef] [PubMed]

36. Department of Health. Refocusing the Care Programme Approach: Policy and Positive Practice Guidance; Department of Health: London, UK, 2008. Available online: https: / / webarchive.nationalarchives.gov.uk/20130124042407/http:/ / www.dh.gov.uk/ prod_consum_dh/groups/dh_digitalassets/@dh/@en/documents/digitalasset/dh_083649.pdf (accessed on 13 May 2021).

37. National Institute for Care and Excellence. Patient Experience in Adult NHS Services: Improving the Experience of Care for People Using Adult NHS Services; Publication No. CG138. 2012. Available online: https://www.nice.org.uk/guidance/cg138 (accessed on 13 May 2021). 
38. World Health Organisation. Mental Health Action Plan 2013-2020; World Health Organisation: Geneva, Switzerland, 2013; Available online: https://www.who.int/mental_health/publications/action_plan/en/on12/05/2020 (accessed on 13 May 2021).

39. Cegala, D.J.; Street, R.L.; Clinch, C.R. The Impact of Patient Participation on Physicians' Information Provision during a Primary Care Medical Interview. Health Commun. 2007, 21, 177-185. [CrossRef] [PubMed]

40. Coulter, A.; Ellins, J. Effectiveness of strategies for informing, educating, and involving patients. BMJ 2007, 335, 24-27. [CrossRef] [PubMed]

41. Crawford, M.J. Systematic review of involving patients in the planning and development of health care. BMJ 2002, $325,1263$. [CrossRef] [PubMed]

42. British Obesity \& Metabolic Surgery Society. Letter to PM. Available online: https://www.bomss.org.uk/ (accessed on 20 May 2020).

43. Smith, J.A.; Flowers, P.; Larkin, M. Interpretative Phenomenological Analysis: Theory, Method and Research; SAGE: Newcastle upon Tyne, UK, 2009.

44. Peat, G.; Rodriguez, A.; Smith, J. Interpretive phenomenological analysis applied to healthcare research. Evid. Based Nurs. 2019, 22, 7-9. [CrossRef] [PubMed]

45. Hammarberg, K.; Kirkman, M.; de Lacey, S. Qualitative research methods: When to use them and how to judge them. Hum. Reprod. 2016, 31, 498-501. [CrossRef]

46. Eatough, V.; Smith, J. I was like a wild wild person: Understanding feelings of anger using interpretative phenomenological analysis. Br. J. Psychol. 2006, 97, 483-498. [CrossRef]

47. Pietkiewicz, I.; Smith, J.A. A practical guide to using Interpretative Phenomenological Analysis in qualitative research psychology. Czas. Psychol. 2012, 20, 361-369. [CrossRef]

48. Townshend, K.; Caltabiano, N.J. The extended nervous system: Affect regulation, somatic and social change processes associated with mindful parenting. BMC Psychol. 2019, 7, 41. [CrossRef]

49. Watson, C.; Riazi, A.; Ratcliffe, D. Exploring the Experiences of Women Who Develop Restrictive Eating Behaviours after Bariatric Surgery. Obes. Surg. 2020, 30, 2131-2139. [CrossRef]

50. Yardley, L. Dilemmas in qualitative health research. Psychol. Health 2000, 15, 215-228. [CrossRef]

51. Booth, H.P.; Khan, O.; Fildes, A.; Prevost, A.T.; Reddy, M.; Charlton, J.; Gulliford, M.C. Changing Epidemiology of Bariatric Surgery in the UK: Cohort Study Using Primary Care. Obes. Surg. 2016, 26, 1900-1905. [CrossRef] [PubMed]

52. Puhl, R.M.; Heuer, C.A. Obesity stigma: Important considerations for public health. Am. J. Public Health 2010, 100, 1019-1028. [CrossRef] [PubMed]

53. Maestre, J.F.; Eikey, E.V.; Warner, M.; Yarosh, S.; Pater, J.; Jacobs, M.; Marcu, G.; Shih, P.C. Conducting research with stigmatized populations: Practices, challenges, and lessons learned. In Proceedings of the CSCW '18: Companion of the 2018 ACM Conference on Computer Supported Cooperative Work and Social Computing, 3-7 November 2018; Association for Computing Machinery: New York, NY, USA, 2018; pp. 385-392.

54. Smith, J.A.; Osborn, M. Chapter 4: Interpretive Phenomenological Analysis. In Qualitative Psychology. A practical Guide to Research Methods; Smith, J.A., Ed.; SAGE: Newcastle upon Tyne, UK, 2008; pp. 53-80.

55. Royal College of Physicians. Action on obesity: Comprehensive care for all. Clin. Med. 2013, 13, 4. Available online: https: //www.rcpjournals.org/content/clinmedicine/13/1/4 (accessed on 13 May 2021). [CrossRef]

56. Owen-Smith, A.; Kipping, R.; Donovan, J.; Hine, C.; Maslen, C.; Coast, J. NICE example- variation in access to morbid obesity surgery in England. BMJ 2013, 346, 21-23. [CrossRef] [PubMed]

57. Welbourn, R.; le Roux, C.W.; Owen-Smith, A.; Wordsworth, S.; Blazeby, J.M. Why the NHS should do more bariatric surgery; how much should we do? BMJ 2016, 353. [CrossRef]

58. Dzeng, E.; Smith, T.J. Rationing Healthcare: Who's Responsible? Oncology 2014, 27, 91-96.

59. McKinstry, B. Paternalism and the doctor-patient relationship in general practice. Br. J. Gen. Pract. J. R. Coll. Gen. Pract. 1992, 42, 340-342.

60. Hall, M.A.; Dugan, E.; Zheng, B.; Mishra, A.K. Trust in Physicians and Medical Institutions: What Is It, Can It Be Measured, and Does It Matter? Milbank Q. 2001, 79, 613-639. [CrossRef]

61. Ommen, O.; Janssen, C.; Neugebauer, E.; Bouillon, B.; Rehm, K.; Rangger, C.; Erli, H.J.; Pfaff, H. Trust, social support and patient type-Associations between patients perceived trust, supportive communication and patients preferences in regard to paternalism, clarification and participation of severely injured patients. Patient Educ. Couns. 2008, 73, 196-204. [CrossRef]

62. King, A.; Hoppe, R.B. Best Practice" for Patient-Centered Communication: A Narrative Review. J. Grad. Med. Educ. 2013, 5, 385-393. [CrossRef] [PubMed]

63. Michie, S.; Miles, J.; Weinman, J. Patient-centredness in chronic illness: What is it and does it matter? Patient Educ. Couns. 2003, 51, 197-206. [CrossRef]

64. Stewart, M.A. Effective physician-patient communication and health outcomes: A review. Can. Med Assoc. J. 1995, 152, 1423-1433.

65. Ogden, J.; Ratcliffe, D.; Snowdon-Carr, V. British Obesity Metabolic Surgery Society endorsed guidelines for psychological support pre- and post-bariatric surgery. Clin. Obes. 2019, 9. [CrossRef] [PubMed]

66. Forsyth, J. Boris Johnson Launches a New Battle of the Bulge. The Times. Available online: https://www.thetimes.co.uk/ (accessed on 13 May 2021). 
67. House of Commons. Covid-19 Response. 18 May 2020. Volume 676. Available online: https://bit.ly/2zOKsec (accessed on 13 May 2021).

68. World Obesity Federation. Obesity and COVID-19: Policy Statement. Available online: https://www.worldobesity.org/news/ obesity-and-covid-19-policy-statement (accessed on 12 May 2020). 